\title{
Investigation and Composition Characterization of a "NiTi-like" Alloy Combining High Temperature Shape Memory and High Entropy
}

\author{
L. Peltier ${ }^{1} \cdot$ P. Lohmuller ${ }^{2} \cdot$ F. Meraghni ${ }^{1} \cdot$ S. Berveiller ${ }^{1} \cdot$ E. Patoor ${ }^{3} \cdot$ \\ P. Laheurte ${ }^{2}$
}

Published online: 4 June 2020

(C) ASM International 2020

\begin{abstract}
New high temperature shape memory alloys with five or more elements are under development and present attractive performances for several functional applications. These active metallic materials are called high entropy and high temperature shape memory alloys (HE-HT-SMAs). This work deals with the characterization of an alloy that combines high temperature shape memory effect and high entropy effect features, a NiCuTiHfZr alloy. The evolution of the phase transformation and the shape memory effect during thermal fatigue was compared with a ternary alloy NiTiZr. Ingots were prepared in a cold crucible and alloys were characterized after thermal cycling at $600 \mathrm{~K}$ without a protective gas atmosphere. Optical microscope, X-ray diffraction, and scanning electron microscopy observations showed the presence of martensite in this unpublished alloy at room temperature. The differential scanning calorimetry (DSC) tests showed that martensitic transformation takes place at high temperature. High temperature thermal cycling was performed during a three-point bending tests under constant load without a protective atmosphere. Thermomechanical results showed that high entropy effects increase the operating behavior at high temperature. Hence this new
\end{abstract}

L. Peltier

laurent.peltier@ensam.eu

1 LEM3, Arts et Métiers Institute of Technology, Université de Lorraine, CNRS, HESAM Université, 4, rue Augustin Fresnel, 57070 Metz, France

2 LEM3, Université de Lorraine, Arts et Métiers Institute of Technology, CNRS, 7, rue Félix Savart, 57070 Metz, France

3 GT-UMI 2958 Georgia Tech-Lorraine, CNRS, 2 rue Marconi, 57070 Metz, France composition of NiCuTiHfZr alloy can be used as an actuator for aerospace and aeronautic application.

Keywords High entropy alloys · High temperature shape memory alloys $\cdot$ Martensitic transformation - Shape memory behavior . Thermal fatigue . Aerospace actuator

\section{Introduction}

For centuries, human civilization struggled to develop new metallic materials, most of which contain a major element $\mathrm{C} \mathrm{Cu}$ for brasses and bronzes, $\mathrm{Fe}$ for steels, and Ni for superalloys) [1,2]. Recently, the concept of high entropy alloy has changed this old conventional metallurgy [3]. These high entropy alloys are composed of a solid solution containing at least five elements, which leads to several effects including severe distortion of the crystalline lattice, sluggish diffusion, and cocktail effect [4]. The equiatomic fraction, proposed in the first work on multi-component alloys, is no longer mandatory [3]. A recent work suggests several predictability criteria for the formation of cold workable single-phase solid solution: valence electron concentration (VEC), the enthalpy of mixing $(\Delta H)$, electronegativity difference, atomic size difference [5-10].

The NiTi shape memory alloys have been studied since the 1960s. They are still employed in various industrial sectors, such as aerospace or biomedical applications [11]. Indeed, their operating performances as functional and active materials are recognized and mastered [12, 13]. Since the 2000s, the properties of this binary alloy have been improved by studying NiTi-X alloys when $\mathrm{X}$ can substitute $\mathrm{Ni}$ by $\mathrm{Co}, \mathrm{Cu}, \mathrm{Pd}, \mathrm{Pt}$ [14-17], or substitute Ti by Hf, Zr [18-20] or both by Nb, Ta, Au [16, 21, 22]. 
Equiatomic or quasi-equiatomic NiTi alloy is not the only shape memory alloy but it is the most studied and therefore a very good candidate for the development of a high entropy shape memory alloy (HE-SMA). Depending on the $\mathrm{Ni}$ content, the NiTi alloy can be austenitic or martensitic at room temperature with a range of martensitic start temperature $\left(\mathrm{M}_{\mathrm{s}}\right)$ ranging from $-100{ }^{\circ} \mathrm{C}(52$ at. $\% \mathrm{Ni})$ to $100{ }^{\circ} \mathrm{C}$ (51 at.\% Ni) [23]. A so-called "NiTi-like" alloy containing at least 5 different elements will be expected to be a high entropy and high temperature shape memory alloy [24].

In 2014, Firstov et al. proposed an original and relevant study devoted to the $\mathrm{Ni}_{50} \mathrm{Ti}_{50}$-like alloys with the following compositions: $(\mathrm{NiCu})_{50}(\mathrm{TiHfZr})_{50}$ [19] and $(\mathrm{NiCoCu})_{50}(-$ TiHfZr $)_{50}$ [25]. In this work, titanium content was reduced and was compensated by $\mathrm{Zr}$ and $\mathrm{Hf}$ elements, whereas $\mathrm{Ni}$ was partially replaced by $\mathrm{Cu}$ and $\mathrm{Co}$. The study of these alloys has shown that they have a reversible austenite/martensite transformation and a functional memory effect. For Firstov et al. [19], the use of high entropy alloys provides an interesting way to improve high temperature shape memory alloy whose weakness is the loss of memory effect during thermal fatigue. In the work of Firstov et al., thermomechanical treatments and their consequences on the $\mathrm{Ni}_{50} \mathrm{Ti}_{50}$-like alloy were not studied. In 2019, Chen et al. [26] studied the alloy proposed by Firstov et al. [25] after a homogenizing treatment. Unfortunately, this alloy does not present anymore shape memory effect at high temperature.

In 2019, some works, such as Canadinc et al. [27], show that $\mathrm{Pd}$ or $\mathrm{Pt}$ can replace $\mathrm{Co}$ or $\mathrm{Cu}$ in the development of HE-HT-SMAs. Unfortunately, the use of precious or semiprecious metals greatly limits the interest of industrials for thermal actuators based on shape memory effect.

The aim of this work is to develop a homogenized quinary alloy with a single phase and a high temperature shape memory effect. The paper presents for the first time an investigation of the thermal fatigue of the developed high entropy HT-SMA and the characterization of its thermomechanical properties. The paper is organized as follows: the first section is devoted to the presentation of the experimental procedure and its application for the melting and casting of a quinary and a ternary NiTi-like alloys. The second section presents the experimental techniques using XRD, SEM, and related devices aiming at characterizing the two HT-SMAs. The third section is devoted to the experimental results and a discussion comparing the high temperature shape memory alloy and the high entropy and high temperature shape memory alloy in terms of thermomechanical properties during thermal fatigue.

\section{Experimental Procedure}

\section{Elaboration Stages and Heat Treatments}

The studied alloys were produced using high purity raw materials; the purity of different metal was greater than 99.9 wt.\% (Fig. 1a). A CFSYS cold crucible (or levitation furnace) combined with a $50 \mathrm{~kW}$ CELES induction furnace was employed for the production of the alloys (Fig. 1b, e, h). It is equipped with a laser pyrometer which measures the melting temperature $\left(\mathrm{T}_{\mathrm{m}}\right)$ of the alloy. Before heating, the cold crucible was evacuated five times to a vacuum pressure of $9 \times 10^{-3}$ mbar and filled back with ultra-pure Argon gas. The melting was carried out in ultra-pure Ar at a pressure of 900 mbar; then the ingot was flipped into the crucible using a «homemade» ejection system (Fig. 1d, g). Ten melting cycles were done to ensure the homogeneity of the produced alloy. The ingot was then casted in a cylindrical mold with a volume of $20 \mathrm{~cm}^{3}$ (as Fig. 1h, i).

These ingots were homogenized and solutioned in a tubular furnace which provides the same atmospheric protection as the cold crucible [28]. This furnace is equipped with a «homemade» device allowing a quick water quenching carried out in ultra-pure argon gas. The heat treatment was performed at $1100{ }^{\circ} \mathrm{C}\left(200{ }^{\circ} \mathrm{C}\right.$ below the melting temperature $T_{\mathrm{m}}$ ), its duration and the quench mode have been optimized experimentally for each alloy.

Three metallurgical states were considered for further characterizations: just after melting (As-Cast or AC), after a solution treatment (ST) followed or not by a water quenching (WQ).

\section{Austenite-Martensite Transformation and Memory Effect Characterization.}

The martensite and austenite start and finish temperatures $\left(\mathrm{M}_{\mathrm{S}}, \mathrm{M}_{\mathrm{f}}, \mathrm{A}_{\mathrm{S}}\right.$ and $\left.\mathrm{A}_{\mathrm{f}}\right)$ were obtained using a SETARAM DSC 131 (Differential Scanning Calorimeter) according to the ASTM standard F2004-17 [29, 30] for NiTi (cooling and heating rate of $\left.10{ }^{\circ} \mathrm{C} / \mathrm{min}\right)$. The enthalpy changes $(\Delta \mathrm{H})$ were obtained using the SETSOFT software.

The microstructure observations were performed using a Zeiss Supra 40 field emission gun scanning electron microscopy (FEG-SEM). The chemical composition of the samples was analyzed by EDX (Energy dispersive X-ray spectrometry) technique.

The crystallographic phases were analyzed by Rigaku $\mathrm{X}$-ray diffraction using $\mathrm{Cu}-\mathrm{K} \alpha$ radiation at room temperature before and after heat treatment (XRD powder mode: an accelerating voltage of $40 \mathrm{kV}$ and an intensity of $30 \mathrm{~mA}$ ). The diffractograms were indexed with a dedicated 
Fig. 1 Melting and casting of HEA NiTi-like: a pure metals pellets; $\mathbf{b}, \mathbf{e}, \mathbf{h}$ melting and levitation; $\mathbf{c}, \mathbf{f}$ cooling into the cold crucible; $\mathbf{d}$, g flipping; i casting into a cylindrical mold

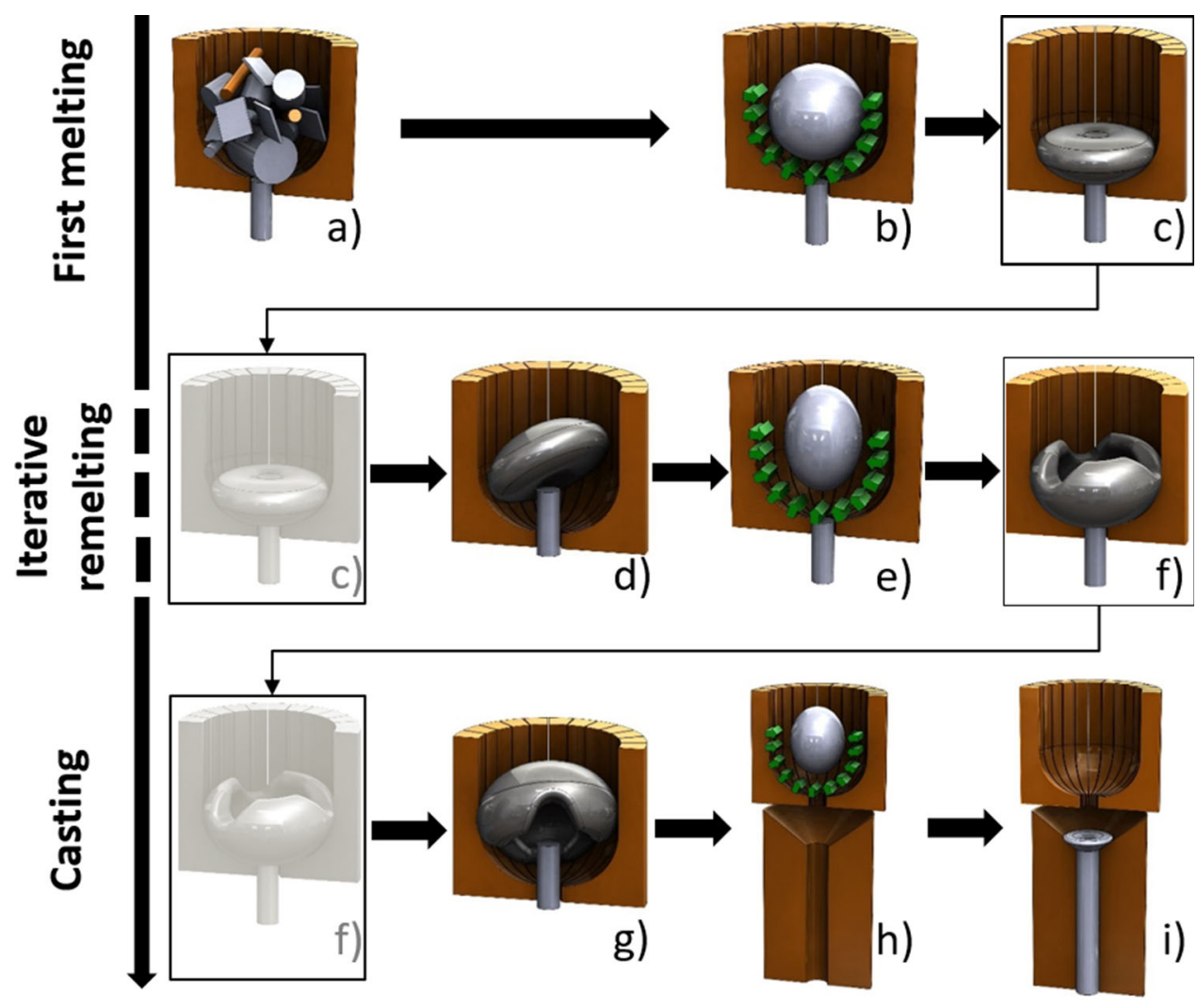

software (Maud) that determines the crystallographic structures and their lattice parameters.

The volume fractions of the different phases in each states of the alloys were obtained by image analysis using ImageJ freeware (provided by National Institute of Health). Each quantification was carried out on 10 representative SEM microphotographs.

\section{Thermal Fatigue Tests}

To analyze the thermal fatigue responses, the two studied alloys (NiCuTiHfZr and NiTiZr) were placed in a thermal shock chamber and were subjected to 200 cycles. Each cycle lasts $60 \mathrm{~min}$, the heating and cooling rates were $10{ }^{\circ} \mathrm{C} / \mathrm{min}$. The maximum temperature of the cycle was $325^{\circ} \mathrm{C}$ and the atmosphere was not protective to mimic an industrial use of the high temperature memory effect. The samples were then analyzed in DSC, XRD, and SEM after different predefined cycle numbers.

In order to demonstrate the memory effect, thermomechanical three-point bending tests were carried out on rectangular plates of $20 \times 4 \times 0.7 \mathrm{~mm}^{3}$. The constant stress tests were performed by applying a static load to the high temperature shape memory alloys; the stress value was equal to $500 \mathrm{MPa}$. The specimen was thermally actuated by heating elements (cooling and heating rate of $20{ }^{\circ} \mathrm{C} / \mathrm{min}$ ). The tests were monitored using a computer connected to a data acquisition device that provides the strain-temperature curve for heating and cooling stages. Three-point bending tests were performed after the predefined cycles number, namely: 1, 50 and 200 (respectively labeled C1, C50, and C200). A schematic view of the device is reported in Fig. 2. It is worth noticing that there are no physical limitations in terms of sample deformation during the cooling phase.

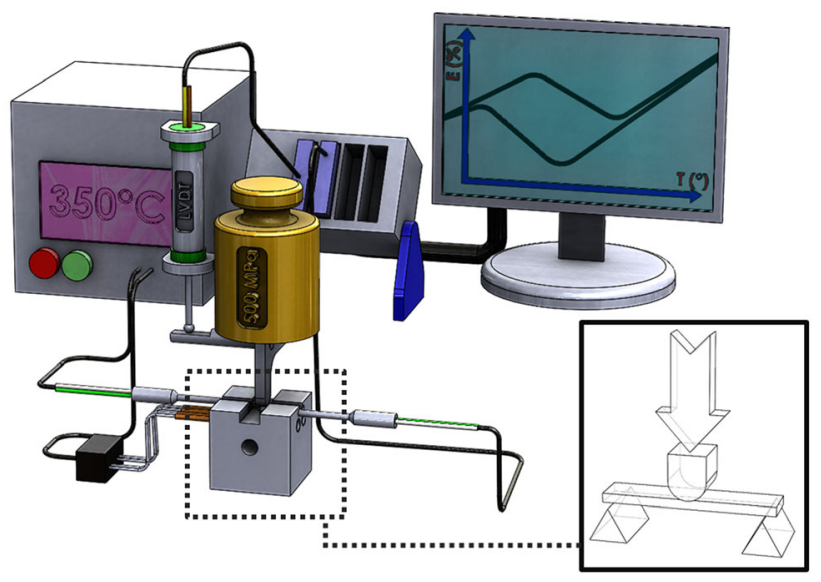

Fig. 2 Schematic layout of the device used to test thermal memory effect of NiTiZr and NiCuTiHfZr alloys 


\section{Preliminary Experimental Results}

In this part, the effects of the thermomechanical treatments on high entropy and high temperature NiTi-Like alloys, before and after the homogenizing treatment are analyzed and discussed. As mentioned before, the $(\mathrm{NiCu})_{50}(-$ TiHfZr $)_{50}$ alloy was produced in the cold crucible, and solutioning it was analyzed by DSC and SEM. The DSC curves reveal peaks of phase transformations only on the "As-cast" state between $25^{\circ} \mathrm{C}$ and $400{ }^{\circ} \mathrm{C}$, but not after solutioning treatment. Moreover, the XRD diffractograms show an increase of the austenitic phase (B2) on the solutioned alloy (Fig. 3). So it seems that the $(\mathrm{NiCu})_{50}(-$ TiHfZr $)_{50}$ alloy cannot be used as a HT-SMA after ST and WQ.

The SEM observations show dendritic globular phase and an interdendritic phase for the as-cast state (Fig. 4a). It contains martensite variants which must have formed during cooling. The composition of the dendritic phase is near-from a HEA- $\mathrm{Ni}_{50} \mathrm{Ti}_{50}$-like alloy, namely $\mathrm{Ni}_{27} \mathrm{Cu}_{23}$ $\mathrm{Ti}_{16} \mathrm{Hf}_{19} \mathrm{Zr}_{15}$ (Fig. 4b). Kosorukova et al. describes how martensite crystals are forming in dendritic regions of $\mathrm{Ni}_{25} \mathrm{Co}_{10} \mathrm{Cu}_{15}(\mathrm{TiZrHf})_{50}$ high entropy shape memory alloy [31].

So, in order to try to get a SMA, an ingot with the same chemical composition as the dendritic phase was elaborated. In the following, we will focus on the
$\mathrm{Ni}_{27} \mathrm{Cu}_{23} \mathrm{Ti}_{16} \mathrm{Hf}_{19} \mathrm{Zr}_{15}$ alloy (Fig. 5b). It is worth mentioning that this composition is different from all proposed elsewhere $[19,25]$ in terms of at.\% contents. The ingot was first homogenized $\left(1000{ }^{\circ} \mathrm{C}\right.$ for $\left.190 \mathrm{~h}\right)$ (Fig. 4c) and next treated in solid solution $\left(900{ }^{\circ} \mathrm{C}\right.$ for $2 \mathrm{~h}$ and water quenched). Results obtained on this alloy are presented in the next part.

\section{Characterization of a New Composition of a HE-HT SMA: Experimental Results and Discussion}

In this part, two alloys were investigated: a quinary alloy $\mathrm{Ni}_{27} \mathrm{Cu}_{23} \mathrm{Ti}_{16} \mathrm{Hf}_{19} \mathrm{Zr}_{15}$ and a ternary alloy $\mathrm{Ni}_{49} \mathrm{Ti}_{33} \mathrm{Zr}_{18}$ [32] which were used as the reference.

\section{HEA criteria determination}

According to Zhou's work based on Boltzmann's assumptions, the high entropy of a multicomponent alloy is only proven if the value of mixing entropy, $\Delta$ Smix, is greater than $1.5 \mathrm{R}$ where $\mathrm{R}$ is the gas constant $\left(\mathrm{R}=8.314 \mathrm{~J} \mathrm{~K}^{-1} \mathrm{~mol}^{-1}\right)$. In Fig. 1 of the work of Zhou et al. [33], it is interesting to note that for a quinary alloy the compositions of the different elements will be between 5 at. $\%$ and 35 at.\%. Several criteria are used in the

\section{(a)}

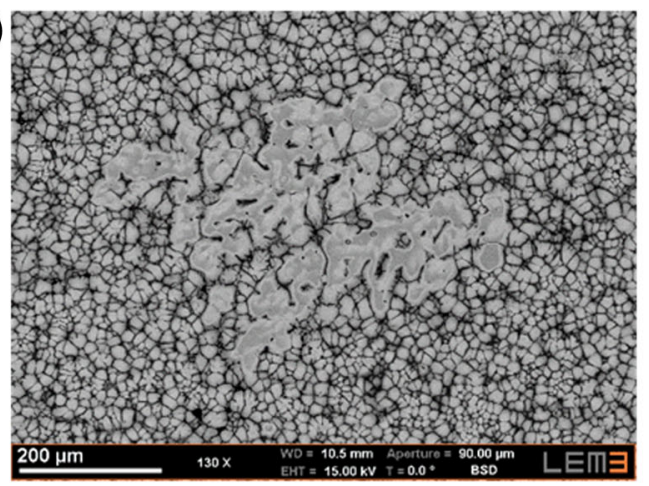

(b)

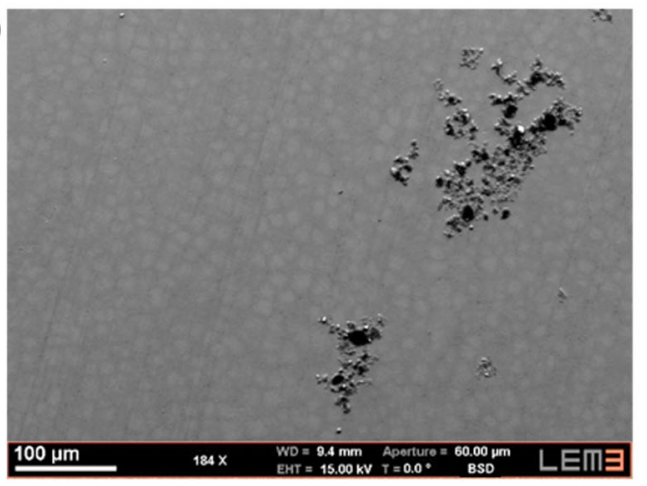

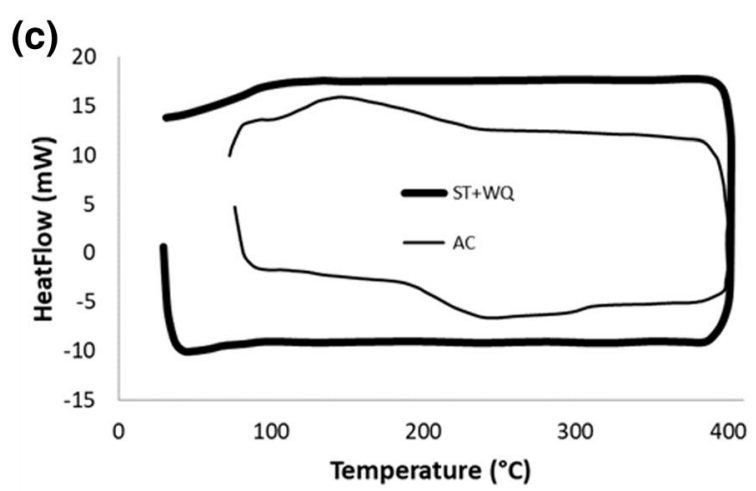

(d)

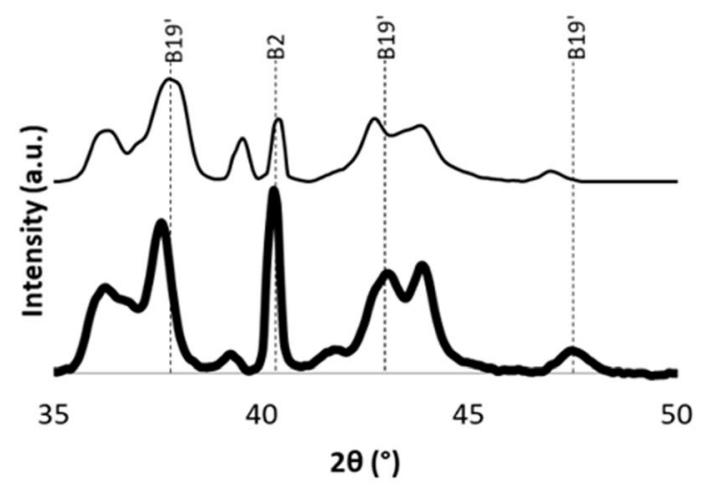

Fig. 3 (NiCu)50(TiHfZr)50 alloy: Microstructure (observed by SEM) a As-cast state; b Solution treated; c DSC curves; d XRD diffractogram 


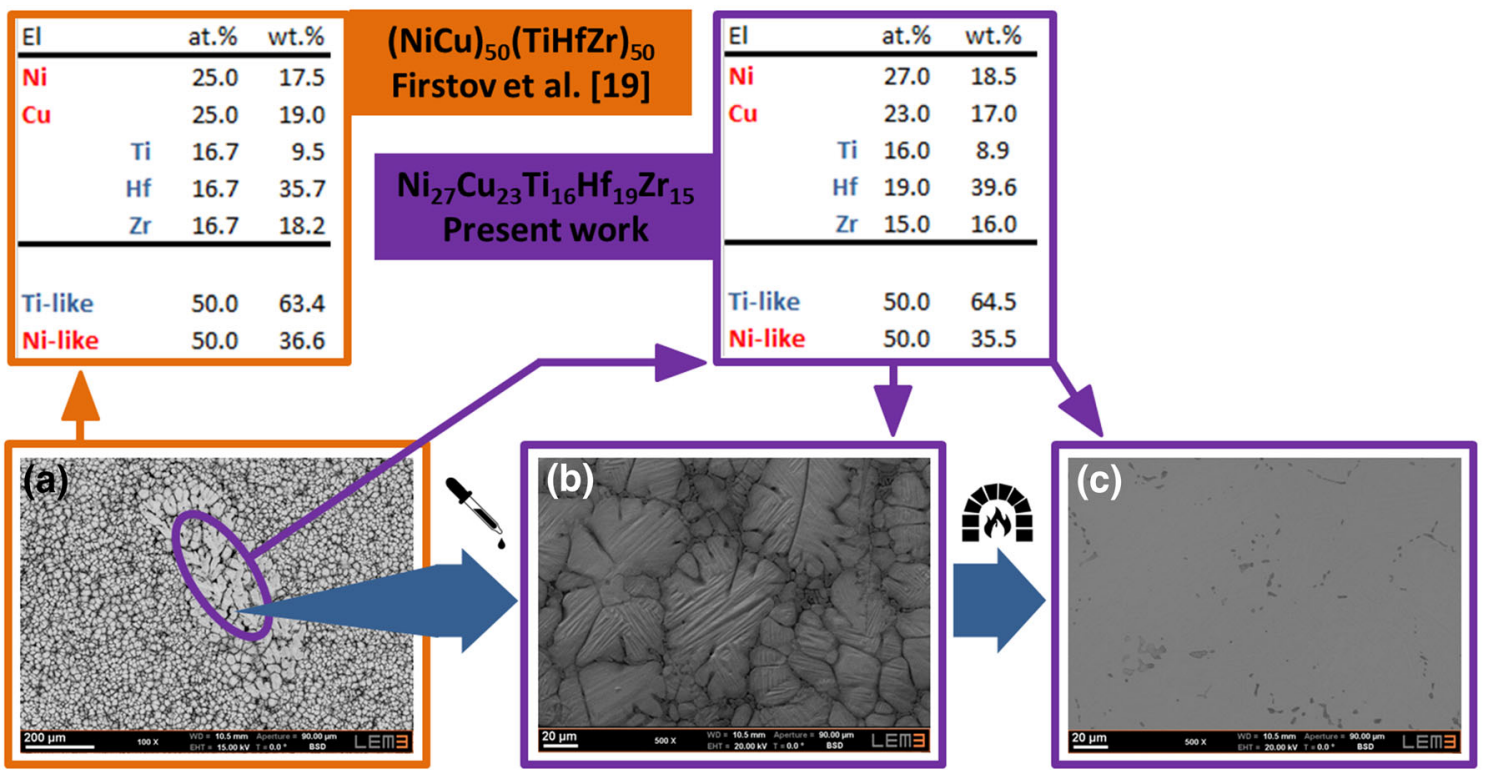

Fig. 4 HE-HT-SMA elaboration: a (NiCu)50(TiHfZr)50 as cast alloy; b Ni27Cu23Ti16Hf19Zr15 as cast alloy; c Ni27Cu23Ti16Hf19Zr15 homogenized state
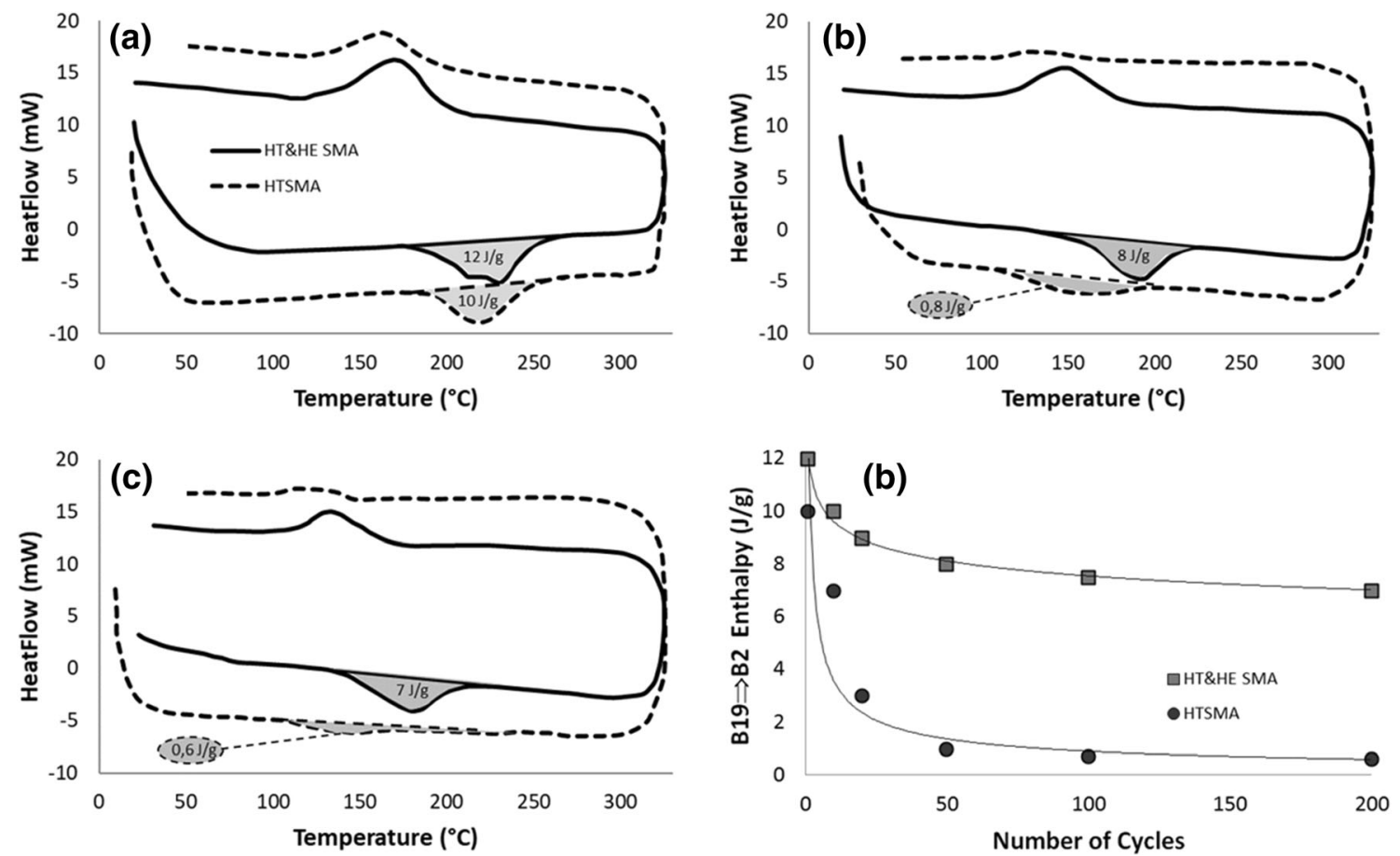

Fig. 5 DSC curves of two alloys during thermal cycle: a cycle 1, b cycle 50; c cycle 200; d Evolution of $\Delta H$

metallurgy of high entropy alloys to increase the predictability of the single-phase solid solution formation. These criteria are based on Hume-Rothery's work [34]. The first criterion is the difference in atomic radius size between the " $n$ " elements that composed the alloy. It is worth mentioning that the integration of the different atoms in the mesh is easier when the difference between atomic radii $(\mathrm{Ra})$ is the smaller. Furthermore, the solubility of the various elements is hence increased whereas the distortion of the mesh is reduced. The second criterion deals with the mixing enthalpy, derived from Gibbs' equation. The term $\Delta$ Hmix represents the average of binary mixing enthalpy obtained with each pair of elements in the alloy. A nearzero or negative enthalpy in Gibbs' equation stabilizes the 
Table 1 Criteria and validation values, in grey obtained values over the range of different criteria

\begin{tabular}{|c|c|c|c|c|c|c|}
\hline \multicolumn{2}{|l|}{ Alloys } & $\begin{array}{c}\Delta \mathrm{Smix} / \mathrm{R} \\
\mathrm{x}>1.5 \\
\end{array}$ & $\begin{array}{c}\Delta \mathrm{Hmix}(\mathrm{kJ} / \mathrm{mol}) \\
\mathrm{x} \in[-10 ; 10]\end{array}$ & $\begin{array}{c}\delta(\%) \\
x \in[0 ; 4] \\
\end{array}$ & $\begin{array}{c}\text { EN Pauling } \\
x \approx 0\end{array}$ & $\begin{array}{c}\text { VEC } \\
x \neq[6.87 ; 7.99] \\
\end{array}$ \\
\hline CrMnFeCoNi & [3] & $1.61 \nabla$ & $-4.16 \square$ & $3.27 \nabla$ & $0.14 \nabla$ & $8.00 \nabla$ \\
\hline (NiCu) $50(\mathrm{TiHfZr}) 50$ & [19] & $1.59 \square$ & $-28.17 区$ & 10.66 区 & $0.27 区$ & $7.25 区$ \\
\hline $\mathrm{Ni25C010Cu15(TiHfZr)50}$ & [25], [26] & $1.76 \square$ & $-31.88 区$ & 10.85 区 & 0.33 区 & 7.05 区 \\
\hline NiзoCu20Ti14.5Hf $21.2 Z r_{14.3}$ & [26] & $1.57 \nabla$ & $-30.78 区$ & 10.85 区 & 0.28 区 & 7.20 区 \\
\hline (NiPd) $50(\mathrm{TiHfZr}) 50$ & [27] & $1.59 \nabla$ & -60.35 区 & 9.40 区 & 0.36 区 & 7.00 区 \\
\hline $\mathrm{Ni}_{27} \mathrm{CU}_{23} \mathrm{Ti}_{16} \mathrm{Hf}_{19} \mathrm{Zr} 15$ & Present work & $1.58 \nabla$ & -29.08 Х & 10.71 区 & 0.27 区 & 7.23 区 \\
\hline
\end{tabular}
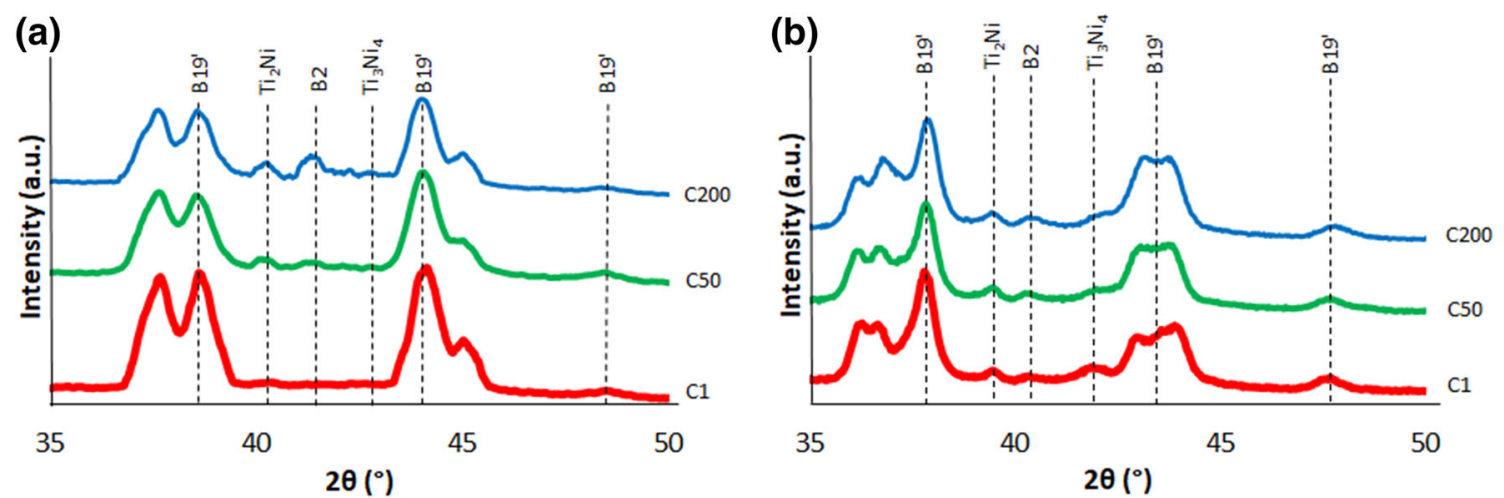

Fig. 6 XRD curves of two alloys during thermal cycle: a NiTiZr; b NiCuTiHfZr

formation of solid solutions. The third criterion is the Pauling's difference in electronegativity between the elements. The fourth criterion focuses of the average of the electrons of valence (Valence Electron Concentration). The third and fourth criteria are used to predict the type of cell generated by the development of a high entropy alloy $[7,35,36]$. Table 1 compares NiTi-like alloys according to the validity of the four criteria proposed to obtain a solid solution. CrMnFeCoCi alloys mainly studied by Cantor et al. [3] fit well with the different criteria and experimental elaboration confirms the formation of a single solid solution. On the opposite, the three other, NiTi-Like alloys present a difference of atomic radii, mixing enthalpy and electronegativity difference over the range prescribed by the criteria (greyed field in Table 1).

\section{Transformation Characterization}

Figure 5a-c show the DSC curves of the two high temperature shape memory alloys up to 200 cycles. $\mathrm{Ni}_{27}$ $\mathrm{Cu}_{23} \mathrm{Ti}_{16} \mathrm{Hf}_{19} \mathrm{Zr}_{15}$ and $\mathrm{Ni}_{49} \mathrm{Ti}_{33} \mathrm{Zr}_{18}$ alloys show a reversible transformation austenite/martensite at high temperature; the HE-HT-SMA has a high enthalpy (about $12 \mathrm{~J} / \mathrm{g}$ ) at the first cycle. The transformation temperatures decrease with cycling for both alloys but these changes are faster for the ternary HTSMA than for the HE-HTSMA.
Figure $5 \mathrm{~d}$ shows the evolution of the heat of transformation during thermal fatigue described below. The heat transformation values are obtained by measuring the area of cooling and heating DSC curves. Figure $5 \mathrm{~d}$ shows that, unlike the $\mathrm{Ni}_{27} \mathrm{Cu}_{23} \mathrm{Ti}_{16} \mathrm{Hf}_{19} \mathrm{Zr}_{15}$ HE-HT-SMA, the heat of transformation of the NiTiZr decreases and reaches a nearzero level after 200 cycles between room temperature and $325{ }^{\circ} \mathrm{C}$. All DSC curves in the study are free of R-phase formation despite high temperature thermal fatigue. With the increasing number of cycles, the temperatures of the transformation points and the transformation heats of the two alloys decrease.

The crystallographic structure of the alloys was identified by XRD at room temperature, as shown in Fig. 6. The XRD pattern shows the existence of the B2 austenite and B19' martensite phases required for shape memory effect $[19,25,37]$. With an increasing number of cycles, it is clearly observed that the fraction of martensite (B19') decreases for the ternary shape memory alloy NiTiZr, while the austenite (B2) fraction increases. Furthermore, one can also identify a slight increase of $\mathrm{Ti}_{2} \mathrm{Ni}$-like intermetallic compounds $\left(\mathrm{MgZn}_{2}\right.$ type ternary Laves phase), which are commonly observed in these alloys [19, 38]. Table 2 shows the cell parameters of the different phases present in the studied alloys. Cells parameters and peak locations of the B2 and B19' phases are in agreement with 
Table 2 Refined cell parameters from X-ray data

\begin{tabular}{|c|c|c|c|c|c|c|c|c|c|}
\hline & \multirow{2}{*}{\multicolumn{2}{|c|}{ Alloys }} & \multirow[t]{2}{*}{ Phase } & \multirow[t]{2}{*}{ Symmetry } & \multirow{2}{*}{$\begin{array}{l}\text { Space } \\
\text { Group }\end{array}$} & \multicolumn{4}{|c|}{$\begin{array}{l}\text { Lattice parameters } \\
\text { Lenghts in } A \quad \text { Angle in }\end{array}$} \\
\hline & & & & & & a & $b$ & $c$ & $\beta$ \\
\hline \multirow{6}{*}{ 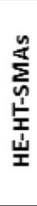 } & \multirow{4}{*}{$\mathrm{Ni}_{27} \mathrm{Cu} 23 \mathrm{Ti} 16 \mathrm{Hf} 19 \mathrm{Zr} 15$} & \multirow{4}{*}{ Present work } & ${\mathrm{B} 19^{\prime}}^{\prime}$ & Monoclinic & $\mathrm{P} 21: \mathrm{m}$ & 3.179 & 4.162 & 5.013 & 102.224 \\
\hline & & & B2 & Cubic & Im-3m & 3.178 & & & \\
\hline & & & $\mathrm{Ti} 2 \mathrm{Ni}$ & Cubic & $\mathrm{Fd}-3 \mathrm{~m}$ & 8.537 & & & \\
\hline & & & $\mathrm{Ti}_{2} \mathrm{Ni}$ & Tetragonal & 14 & 3.108 & & 3.108 & \\
\hline & \multirow{2}{*}{$(\mathrm{NiCu}) 50(\mathrm{TiHfZr}) 50$} & \multirow{2}{*}[18,25]{} & ${\mathrm{B} 19^{\prime}}^{\prime}$ & Monoclinic & $\mathrm{P} 21: \mathrm{m}$ & 3.155 & 4.167 & 4.967 & 100.950 \\
\hline & & & B2 & Cubic & Im-3m & 3.167 & & & \\
\hline \multirow{6}{*}{ 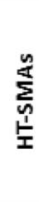 } & \multirow{4}{*}{ Ni49Ti33Zr18 } & \multirow{4}{*}{$\begin{array}{l}\text { Present work, } \\
\text { [30] }\end{array}$} & B19' & Monoclinic & $\mathrm{P} 21: \mathrm{m}$ & 3.189 & 4.122 & 5.040 & 102.490 \\
\hline & & & B2 & Cubic & Im-3m & 3.163 & & & \\
\hline & & & $\mathrm{Ti} 2 \mathrm{Ni}$ & Cubic & $\mathrm{Fd}-3 \mathrm{~m}$ & 8.451 & & & \\
\hline & & & $\mathrm{Ti}_{2} \mathrm{Ni}$ & Tetragonal & 14 & 3.108 & & 3.108 & \\
\hline & \multirow{2}{*}{ Ni50Ti30Zr20 } & \multirow{2}{*}[38,39]{} & B19' & Monoclinic & $\mathrm{P} 21: \mathrm{m}$ & 3.077 & 4.075 & 4.925 & 103.930 \\
\hline & & & B2 & Cubic & Im-3m & & & & \\
\hline
\end{tabular}

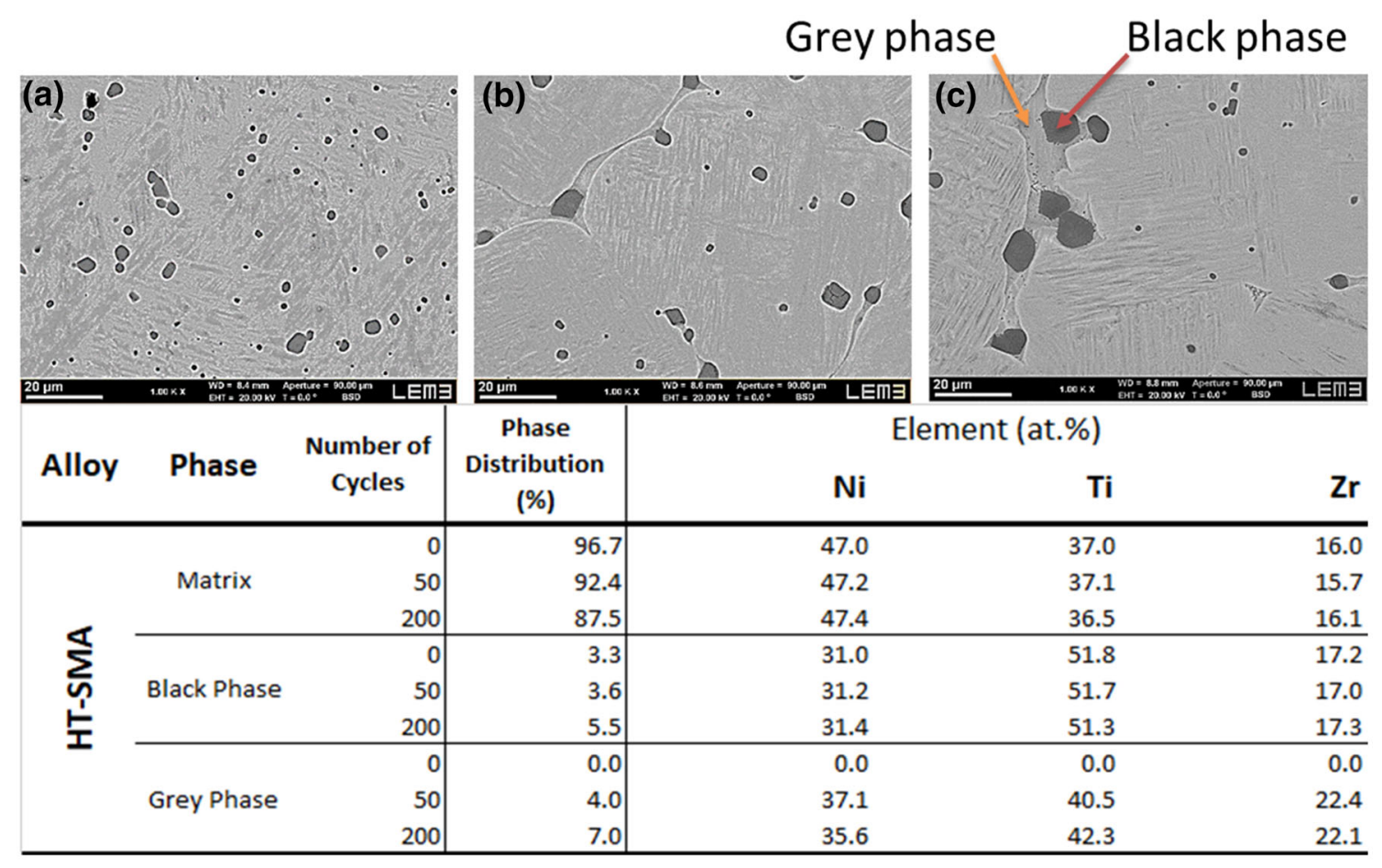

Fig. 7 EDX distribution of phases in NiTiZr as a function of cycles number: a 1 cycle; b 50 cycles; c 200 cycles

those observed by $[32,39]$. We can show a very slight difference between our results and the work of Carl et al. [40] and Firstov et al. [25, 37]. These slight differences in cell parameters can be explained by the small variations of atomic content of different elements between the ternary and quinary alloys.

The SEM investigations show an increase in composition heterogeneity and an evolution in phases, especially for the ternary alloy. The quinary alloy shows a great stability throughout the study. The composition and the distribution of the phases are summarized in Fig. 7 for NiTiZr and Fig. 8 for NiCuTiHfZr.

In the case of NiTiZr alloy (Fig. 7), we can notice that two phases are present at C200 in addition to the matrix: a "black" and a "grey" phase. The "black" phase is very rich in $\mathrm{Ti}$, it was present before cycling and its fraction remains stable even after 200 cycles. The "grey" phase appears during cycling (before C50) and grows at the grain boundaries. There are large similarities between Fig. $7 \mathrm{~b}$ reported in Firstov et al. [41] and Fig. 7a obtained in the present study. The difference in the chemical composition 


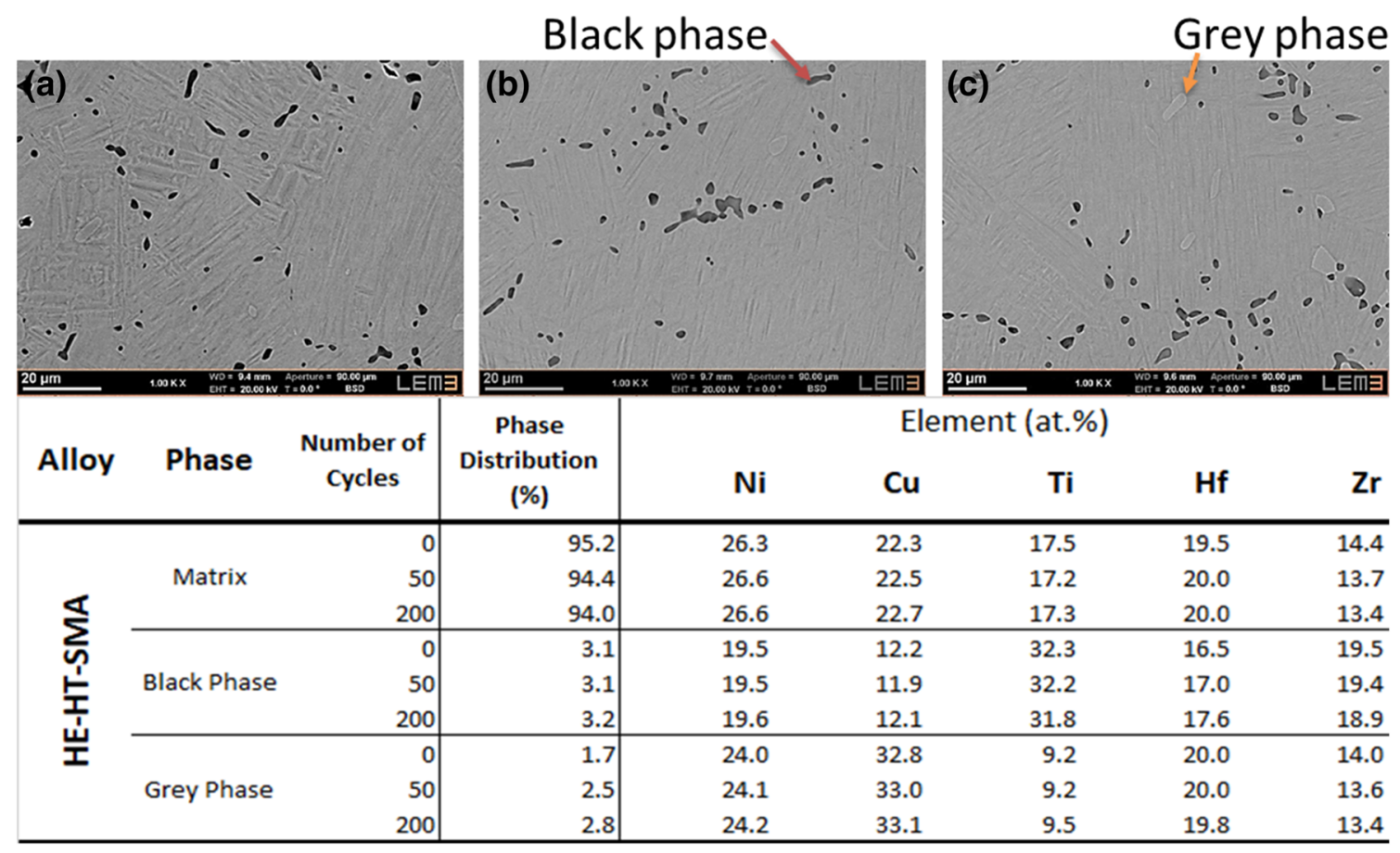

Fig. 8 EDX distribution of phases in NiCuTiHfZr: a 1 cycle; b 50 cycles; c 200 cycles

of the "black" phase and the vanishing "grey" phase can be explained by the difference between the heat treatments, which are higher temperature and longer duration in the present study.

Table1 showed us that the NiCuTiHfZr alloy did not validate the predictability criteria for solid solution formation and Fig. 8 confirms that the alloy is not a single phase but this figure shows us a majority phase. Besides the matrix, we can observe two phases at C200: a "black" phase very rich in $\mathrm{Ti}$ and poor in $\mathrm{Ni}$, and a "grey" phase rich in $\mathrm{Cu}$ and very poor in $\mathrm{Ti}$. It is worth noticing that the "black" phase in both alloys is similar to $\mathrm{Ti}_{2} \mathrm{Ni}$-like or $(\mathrm{TiHfZr})_{2}(\mathrm{NiCu})^{2}[26]$ and the grey phase is similar to $\mathrm{Ti}_{3} \mathrm{Ni}_{4}$-like or $(\mathrm{TiHfZr})_{3}(\mathrm{NiCu})_{4}$ [42-44], which is consistent with both XRD diffractograms indexing shown in Fig. 6a, b.

\section{High Temperature Memory effect}

Figure 9b, c show the shape memory effect of conventional ternary high temperature $\mathrm{Ni}_{49} \mathrm{Ti}_{33} \mathrm{Zr}_{19}$ and quinary high entropy and high temperature $\mathrm{Ni}_{27} \mathrm{Cu}_{23} \mathrm{Ti}_{16} \mathrm{Hf}_{19} \mathrm{Zr}_{15}$ under flexural stresses of $500 \mathrm{MPa}$ applied in a three-point bending configuration test. The shape memory effect (SME) is tested after thermal cycling, respectively, C1, C50, and $\mathrm{C} 200$. For the $\mathrm{Ni}_{27} \mathrm{Cu}_{23} \mathrm{Ti}_{16} \mathrm{Hf}_{19} \mathrm{Zr}_{15}$ specimen shown in Fig. 9b, the maximum reversible strain $\left(\varepsilon_{\mathrm{r}}\right)$ is up to $2 \%$ whereas no irreversible strain (cirr) is observed. On the other hand, the strain response of the $\mathrm{Ni}_{49} \mathrm{Ti}_{33} \mathrm{Zr}_{19}$ alloy shown in Fig. 9c exhibits a large reversible strain $\left(\varepsilon_{\mathrm{r}}\right)$ and an irreversible strain $\left(\varepsilon_{\text {irr }}\right)$ up to $3.5 \%$ at $\mathrm{C} 1$ and $1.7 \%$ at C200 when subjected to the constant stress level of $500 \mathrm{MPa}$. From Fig. 9, we can deduce that both alloys exhibit reversible martensitic transformation under constant load.

The measured recoverable strain on the NiCuTiHfZr is relatively low compared to those generally measured for other low temperature SMAs. Nevertheless, it should be reported that the operating performance at high temperature is higher than that observed for all classes of studied shape memory alloys [19, 26, 27]. On one hand, the sluggish diffusion justifies partially the origin of the long service life of the high entropy alloy and on the other hand, the severe distortion of the crystalline lattice explains the origin of the observed low memory effect. Figure 9 shows the great drift of the transformation points for NiTiZr and confirms the DSC results which show this same drift and the fact that the memory effect decreases from the fiftieth thermal cycle for this alloy. Indeed, EDX analyses highlight the existence of several other phases at C200, which then modify the composition of the matrix and induce the decrease of the shape recovery. During the stress bending tests of the HTSMAs, other phenomena appear and block the shape memory effect. In fact, an irreversible plastic strain accompanies the martensite reorientation and the stress induced martensite formation. This plastic strain has been generally noticed in the NiTiZr $[32,41]$. Compared to the NiTiZr alloy, the HE-HT SMA is much more stable at 

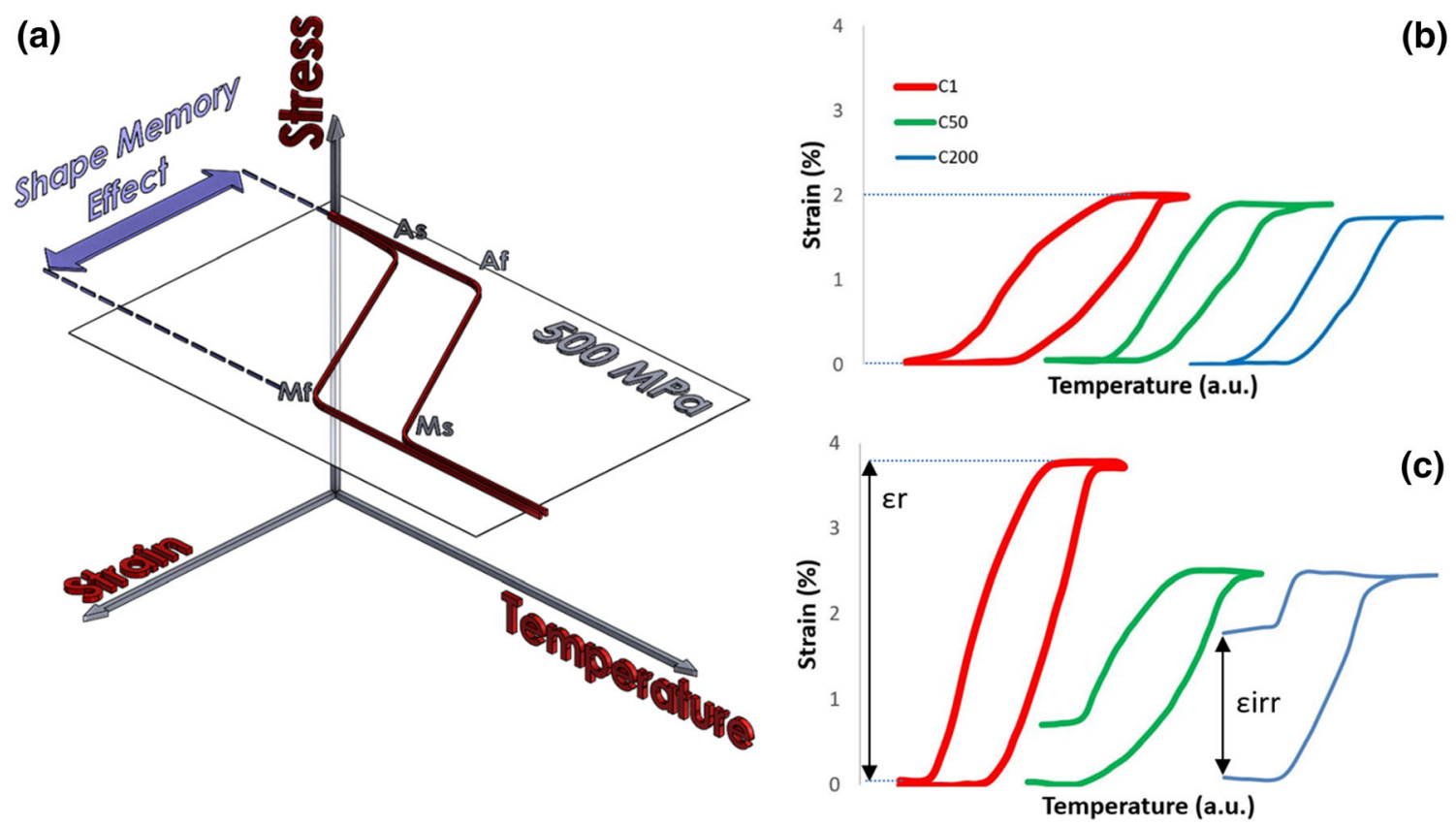

Fig. 9 SME curves of two alloys during the thermal cycle: a schematic diagram, b Ni27Cu23Ti16Hf19Zr15 alloy and c Ni49Ti33Zr19 alloy

high temperature throughout the study and this observation is valid for all performed methods of characterization.

\section{Concluding remarks}

Two shape memory alloys were produced, characterized and compared; a ternary (NiTiZr) and quinary alloy (NiCuTiHfZr). The first is a high temperature shape memory alloy (HT-SMA) whereas the second one is a high entropy and high temperature shape memory alloy (HEHT-SMA). These two alloys have been investigated experimentally in terms of composition, martensitic transformation, and mechanical responses during thermal fatigue. The analysis and the comparison of the obtained experimental results lead to the following concluding remarks:

(1) After a thermomechanical treatment, the developed high entropy NiTi-like alloys during this study exhibit a near single-phase solid solution while they do not verify all the established criteria that lead to a workable high entropy alloy.

(2) After the first thermal cycle, the temperatures of the transformation points and the transformation heats of $\mathrm{Ni}_{27} \mathrm{Cu}_{23} \mathrm{Ti}_{16} \mathrm{Hf}_{19} \mathrm{Zr}_{15}$ and $\mathrm{Ni}_{49} \mathrm{Ti}_{33} \mathrm{Zr}_{18}$ are very close and have the same range.

(3) All the characterization methods confirm the decrease or loss of the shape memory effect for the ternary alloy from the tenth thermal cycle.
(4) Moreover, the performed investigation techniques confirm the very high stability of the memory effect of the quinary alloy until 200 cycles.

Finally, this study shows that the advantages of high entropy alloys can fill the chemical deficiencies of conventional high temperature shape memory alloys. The sluggish diffusion, one of the effects resulting from high entropy, seems to be the effect that contributes to improve the performance of HE-HT-SMA in service during thermal cycling. In addition, it is worth mentioning that, the severe distortion of the mesh and the cocktail effect do not penalize nor reduce the memory effect. The fact that the memory effect of the HT-HE-SMA is unchanged after 200 thermal cycles (between 25 and $325^{\circ} \mathrm{C}$ ) without gaseous protection suggests that the developed alloy can be used efficiently for high temperature actuators (600 K).

Acknowledgements This research was supported by the SMART team of the laboratory LEM3. We thank warmly our colleagues P. Charbonnier, P. Moll, O. Perroud and J. Slowensky who provided help and expertise that strongly assisted this study.

\section{References}

1. De Ryck I, Adriaens A, Adams F (2005) An overview of Mesopotamian bronze metallurgy during the 3rd millennium BC. J Cult Herit 6:261-268. https://doi.org/10.1016/j.culher.2005.04. 002

2. Kraner J, Lazar T, Zorc B, Fajfar P, Knap M (2019) Archaeometallurgical characterization of a 16th century suit of armour made by Valentin Siebenbürger. J Cult Herit. https://doi. org/10.1016/j.culher.2019.02.013 
3. Cantor B, Chang ITH, Knight P, Vincent AJB (2004) Microstructural development in equiatomic multicomponent alloys. Mater Sci Eng A 375-377:213-218. https://doi.org/10. 1016/j.msea.2003.10.257

4. Chen J, Zhou X, Wang W, Liu B, Lv Y, Yang W, Xu D, Liu Y (2018) A review on fundamental of high entropy alloys with promising high-temperature properties. J Alloys Compd 760:15-30. https://doi.org/10.1016/j.jallcom.2018.05.067

5. Guo S, Liu CT (2011) Phase stability in high entropy alloys: formation of solid-solution phase or amorphous phase. Prog Nat Sci Mater Int 21:433-446. https://doi.org/10.1016/S10020071(12)60080-X

6. Guo S, Hu Q, Ng C, Liu CT (2013) More than entropy in highentropy alloys: forming solid solutions or amorphous phase. Intermetallics 41:96-103. https://doi.org/10.1016/j.intermet.2013. 05.002

7. Yeh JW (2013) Alloy design strategies and future trends in highentropy alloys. Jom 65:1759-1771. https://doi.org/10.1007/ s11837-013-0761-6

8. Ye YF, Wang Q, Zhao YL, He QF, Lu J, Yang Y (2016) Elemental segregation in solid-solution high-entropy alloys: experiments and modeling. J Alloys Compd 681:167-174. https://doi. org/10.1016/j.jallcom.2016.04.239

9. Lohmuller P, Peltier L, Hazotte A, Zollinger J, Laheurte P, Fleury E (2018) Variations of the elastic properties of the CoCrFeMnNi high entropy alloy deformed by groove cold rolling. Materials (Basel) 11:1337. https://doi.org/10.3390/ma11081337

10. LaRosa CR, Shih M, Varvenne C, Ghazisaeidi M (2019) Solid solution strengthening theories of high-entropy alloys. Mater Charact 151:310-317. https://doi.org/10.1016/j.matchar.2019.02. 034

11. Hartl DJ, Lagoudas DC (2007) Aerospace applications of shape memory alloys. Proc Inst Mech Eng Part G: J Aerosp Eng 221:535-552. https://doi.org/10.1243/09544100JAERO211

12. Duerig T, PeltonA, Sto D (1999) 3991284-Principios-de-Ingenieria-de-Cimentaciones.pdf 275:149-160. https://doi.org/10. 1016/S0921-5093(99)00294-4

13. Mohd Jani J, Leary M, Subic A, Gibson MA (2014) A review of shape memory alloy research, applications and opportunities. Mater Des 56:1078-1113. https://doi.org/10.1016/j.matdes.2013. 11.084

14. Huang X, Norwich DW, Ehrlinspiel M (2014) Corrosion behavior of Ti-55Ni-1.2Co high stiffness shape memory alloys. J. Mater. Eng. Perform. 23:2630-2634. https://doi.org/10.1007/s11665014-1014-8

15. Goryczka T, Van Humbeeck J (2006) Characterization of a NiTiCu shape memory alloy produced by powder technology. J Achiev Mater Manuf Eng 17:65-68

16. Khaleghi F, Tajally M, Emadoddin E, Mohri M (2019) The investigation of the mechanical properties of graded high-temperature shape memory Ti-Ni-Pd alloy. J Alloys Compd 787:882-892. https://doi.org/10.1016/j.jallcom.2019.02.142

17. Lin B, Gall K, Maier HJ, Waldron R (2009) Structure and thermomechanical behavior of NiTiPt shape memory alloy wires. Acta Biomater 5:257-267. https://doi.org/10.1016/j.actbio.2008. 07.015

18. Prasad RVS, Park CH, Kim SW, Hong JK, Yeom JT (2017) Microstructure and phase transformation behavior of a new high temperature NiTiHf-Ta shape memory alloy with excellent formability. J Alloys Compd 697:55-61. https://doi.org/10.1016/ j.jallcom.2016.12.129

19. Firstov GS, Kosorukova TA, Koval YN, Odnosum VV (2015) High entropy shape memory alloys. Mater Today Proc 2:S499S503. https://doi.org/10.1016/j.matpr.2015.07.335

20. Ley NA, Smith J, Wheeler RW, Young ML (2019) Effects of thermo-mechanical processing on precipitate evolution in $\mathrm{Ni}$-rich high temperature shape memory alloys. Materialia 8:100496. https://doi.org/10.1016/j.mtla.2019.100496

21. Chyiko EA, Wang X, Van Humbeeck J, Kustov S (2017) Isothermal martensitic transformation in ternary $\mathrm{NiTiNb}$ alloy. Mater Today Proc 4:4763-4767. https://doi.org/10.1016/j.matpr. 2017.04.067

22. Casalena L, Bigelow GS, Gao Y, Benafan O, Noebe RD, Wang Y, Mills MJ (2017) Mechanical behavior and microstructural analysis of NiTi-40Au shape memory alloys exhibiting work output above $400{ }^{\circ} \mathrm{C}$. Intermetallics 86:33-44. https://doi.org/10. 1016/j.intermet.2017.03.005

23. Frenzel J, George EP, Dlouhy A, Somsen C, Wagner MFX, Eggeler G (2010) Influence of $\mathrm{Ni}$ on martensitic phase transformations in NiTi shape memory alloys. Acta Mater 58:3444-3458. https://doi.org/10.1016/j.actamat.2010.02.019

24. Chilnicean G, Novac A, Sprincenatu R, Bolocan V, Craciunescu C (2018) Ti-Ta high temperature shape memory alloys. IOP Conf Ser Mater Sci Eng 416:2-10. https://doi.org/10.1088/1757-899X/ 416/1/012017

25. Firstov GS, Kosorukova TA, Koval YN, Verhovlyuk PA (2015) Directions for high-temperature shape memory alloys' improvement: straight way to high-entropy materials? Shape Mem Superelasticity 1:400-407. https://doi.org/10.1007/s40830-0150039-7

26. Chen CH, Chen YJ (2019) Shape memory characteristics of (TiZrHf)50Ni25Co10Cu15 high entropy shape memory alloy. Scr Mater 162:185-189. https://doi.org/10.1016/j.scriptamat.2018.11. 023

27. Canadinc D, Trehern W, Ma J, Karaman I, Sun F (2019) Ultrahigh temperature multi-component shape memory alloys. Scripta Mater 158:83-87. https://doi.org/10.1016/j.scriptamat.2018.08. 019

28. Elmay W, Prima F, Gloriant T, Bolle B, Zhong Y, Patoor E, Laheurte P (2013) Effects of thermomechanical process on the microstructure and mechanical properties of a fully martensitic titanium-based biomedical alloy. J Mech Behav Biomed Mater 18:47-56. https://doi.org/10.1016/j.jmbbm.2012.10.018

29. Pour BA, Client N, ASTM FCN 2004 (2008)

30. Sczerzenie F (2015) Consideration of the ASTM Standards for $\mathrm{Ni}-\mathrm{Ti}$ Alloys Consideration of the ASTM Standards for Ni - Ti Alloys*

31. Kosorukova TA, Gerstein G, Odnosum VV, Koval YN, Maier HJ, Firstov GS (2019) Microstructure formation in cast TiZrHfCo$\mathrm{NiCu}$ and CoNiCuAlGaIn high entropy shape memory alloys: a comparison. Materials (Basel) 12:4227. https://doi.org/10.3390/ ma1224227

32. Firstov GS, Van Humbeeck J, Koval YN (2004) Comparison of high temperature shape memory behaviour for $\mathrm{ZrCu}$-based, Ti$\mathrm{Ni}-\mathrm{Zr}$ and Ti-Ni-Hf alloys. Scr Mater 50:243-248. https://doi.org/ 10.1016/j.scriptamat.2003.09.010

33. Zhou Y, Zhou D, Jin X, Zhang L, Du X, Li B (2018) Design of non-equiatomic medium-entropy alloys. Sci Rep 8:1-9. https:// doi.org/10.1038/s41598-018-19449-0

34. Hume-Rothery W (1966) Atomic diameters, atomic volumes and solid solubility relations in alloys. Acta Metall 14:17-20. https:// doi.org/10.1016/0001-6160(66)90267-7

35. Zhang Y, Zhou YJ, Lin JP, Chen GL, Liaw PK (2008) Solidsolution phase formation rules for multi-component alloys. Adv Eng Mater 10:534-538. https://doi.org/10.1002/adem.200700240

36. Guo S, Ng C, Lu J, Liu CT (2011) Effect of valence electron concentration on stability of fcc or bcc phase in high entropy alloys. J. Appl. Phys. 109:103505. https://doi.org/10.1063/1. 3587228

37. Firstova G, Timoshevski A, Kosorukova T, Koval Y, Matviychuk Y, Verhovlyuk P (2015) Electronic and crystal structure of the high entropy TiZrHfCoNiCu intermetallics undergoing 
martensitic transformation. MATEC Web Conf 33:3. https://doi. org/10.1051/matecconf/20153306006

38. Gupta KP (1999) The Ni-Ti-Zr System. J Phase Equilibria 20:441-448

39. Bertheville B (2005) Powder metallurgical processing of ternary Ni50Ti 50-xZrx (x = 5, 10 at.\%) alloys. J. Alloys Compd. 398:94-99. https://doi.org/10.1016/j.jallcom.2005.02.031

40. Carl M, Smith J, Van Doren B, Young M (2017) Effect of Nicontent on the transformation temperatures in NiTi-20 at $\% \mathrm{Zr}$ high temperature shape memory alloys. Metals (Basel) 7:511. https://doi.org/10.3390/met7110511

41. Firstova G (2004) High-temperature shape memory alloys: Some recent developments. Mater Sci Eng A 378:2-10. https://doi.org/ 10.1016/j.msea.2003.10.324
42. Otsuka K, Ren X (2005) Physical metallurgy of Ti-Ni-based shape memory alloys. Prog Mater Sci 50:511-678. https://doi. org/10.1016/j.pmatsci.2004.10.001

43. Lang P, Wojcik T, Povoden-Karadeniz E, Cirstea CD, Kozeschnik E (2014) Crystal structure and free energy of $\mathrm{Ti}_{2} \mathrm{Ni}_{3}$ precipitates in $\mathrm{Ti}-\mathrm{Ni}$ alloys from first principles. Comput Mater Sci 93:46-49. https://doi.org/10.1016/j.commatsci.2014.06.019

44. Karlík M, Haušild P, Beran P, Novák P, Čapek J, Kučera V, Kopeček J (2015) Phase evolution in Ni-48 AT\% TI shape memory alloy prepared by selfpropagating high-temperature synthesis. Met 2015-24th Int Conf Metall Mater Conf Proc 2-7

Publisher's Note Springer Nature remains neutral with regard to jurisdictional claims in published maps and institutional affiliations. 